\title{
Investigating Design Strategies for Regenerative Development
}

\author{
Dorcas A. Ayeni and Victory O. Omeiza
}

\begin{abstract}
The menace of environmental dilapidation has been an issue of great concern in the built environment since the wake of the industrial revolution. Buildings have been said to be instruments that cut short the natural cycles of resources in both the human and natural ecosystem due to man's anthropocentric mind-set and activities. Various theories, framework, and models have been proposed to facilitate regeneratively sustainable developments. This paper aims at highlighting strategies that are currently practiced in regenerative development with a view of presenting ideas for the practical application of regenerative sustainability in all its facets and phases. Relevant literature that described the processes of creating a regenerative development and the aspects in which regenerative sustainability principles are implemented were reviewed. The design strategies employed in the studied cases were described as they related to the phases and then grouped into the four facets of regenerative development. The paper, therefore, gives an idea of the various integrative element and practical strategies for the implementation of regenerative design in all its phases and facets. Clarity on the subject of regenerative development is also anticipated as examples of regenerative design element implemented in the cases under study were detailed out. These strategies, when applied with attention to place patterns and potentials in all aspects of the built environment, will help in creating a truly regenerative development in any area.
\end{abstract}

Index Terms - Design Strategies; Place; Regenerative Development; Regenerative Sustainability.

\section{INTRODUCTION}

A primary and recent issue drawing more attention for four decades now has been on the constraints facing the environment. These issues known as environmental degradation has been said to take a massive downturn since the wake of the industrial revolution [1]. Reference [25] explained that increased innovations and thoughts have made us separate the environment into a different compartment to be harnessed and exploited by various interested individuals. They emphasized a "disconnect" between humans, (seen in man's developments and buildings) and the entire system of life (nature). There has therefore been an urgency in humans to save the ecosystem from the numerous environmental challenges [2].

Furthermore, [3] explained that the human race at present is the first to transform the environment through science and technology, explaining that various habitats in the environment are being destroyed by the microbial and atomic bomb and the emission of chemicals from man's activities and developments. In addition, [3] stressed that various climatic changes, global warming, deforestation and fundamentally an obliteration of biodiversity, characterizes the environment in this era. Also, [27] highlighted that the source of almost all energy consumption, pollution, and natural resource depletion are found in the lifestyles of humans in the environment. This ever-increasing awareness of man's massive changes to the environment suggests the need for a basic change in man's ways of living and developments. This idea of change has begun to be implemented by some members of the environmental professionals by the creation of sustainable designs for the development of the environment [3], [27].

Responses to the early sustainability theory produced two major paradigms: The Technological and Regenerative for the two-existing worldview in Sustainability: The mechanistic and ecological worldview respectively [28], [5], [15]. Sustainability has been defined differently in these world views and it has been argued that Technological Sustainability due to its anthropocentricity, mechanistic and reductionist nature cannot effectively solve the issue of environmental degradation faced in the 21st Century [6] as it focuses on doing "less harm" to the environment [4]. Technological Sustainability only reduces man's footprint on the environment but do not necessarily restore the lost connection between man and his environment and the already depleting natural resources in the environment which is our goal [5]. Validating the proposition that Regenerative Sustainability in designs and development is the best for the health of the ecosystem, it has been confirmed that it focuses on protecting microclimate, rejuvenating the ecosystem, enhancing human-ecosystem interdependence, avoiding emissions and at the same time, developing the socio-cultural and economic aspects of life through a whole system approach in design [6], [14], [28].

The understanding and framing of a whole system relationship are therefore needed [7], and this is what Regenerative development comes to emphasize. As a means of achieving the whole-system living, Regenerative development is hinged on creating a mutually rewarding association between the human and natural ecosystem. This is achieved through its core principles as processes to design such as understanding and identifying the intrinsic pattern of the local eco-system on the site and employing place-based design strategies for the health of the whole system [15], [5].

Despite the recent expansion and application of the 
principles of regenerative development, there seems to be a lack of clarity concerning its practical application in all its phases and facets in Nigeria. The lack of clarity is noticed from the limited amount of publication existing in developing countries on the same subject of regenerative sustainability which has been a recent high-level sustainability discussion among design practitioners in the developed world. Furthermore, only few groupings of design strategies into all facets and phases of regenerative development has been done to facilitate easy understanding of its principles.

The paper, therefore, seeks to highlight some strategies that are currently practiced in regenerative development with a view of presenting ideas for the practical application of regenerative sustainability in all its facets and phases. Progressively, the paper answers the following: What processes are involved in creating regenerative development? What aspects are needed for a whole system and integrative regenerative development? Finally, what strategies are applied in the studied cases to follow the phases and cover all aspects of regenerative development? Thus, the meaning and principles of regenerative development are explained, the process of creating regenerative development is specified, after which the regenerative strategies employed in the case studies are detailed out. The paper is highly needful as it gives an idea of the various integrative element and practical strategies for the implementation of regenerative design in all its phases and facets. The list of regenerative design strategies is inexhaustible, hence the paper highlights only the strategies employed in the design of four buildings under the Perk ins+Will's regenerative design framework.

\section{MATERIALS AND METHODS}

Relevant case studies and works of literature have been discussed in the literature review; outlining the phases and facets involved in creating regenerative development. The design strategies: an outcome of decisions based on place patterns and potentials were discussed under each facet (green, grey, red, and blue infrastructures) of regenerative development as applied in the examined cases. The Emancipation Park Expansion and Renovation shown in Fig. 1, Vandusen Botanical Garden Visitor Centre shown in Fig. 2, Centre for Urban Waters shown in Fig. 3, and the Life Science Building for the University of Washington shown in Fig. 4, were discussed. They were designed using the Perkins+Will regenerative development framework. The design narrative given by the Perkins+Will architects describing each case were critically reviewed for specific regenerative design strategies. This is done as there are no indigenous building that holistically applies the regenerative development principles.

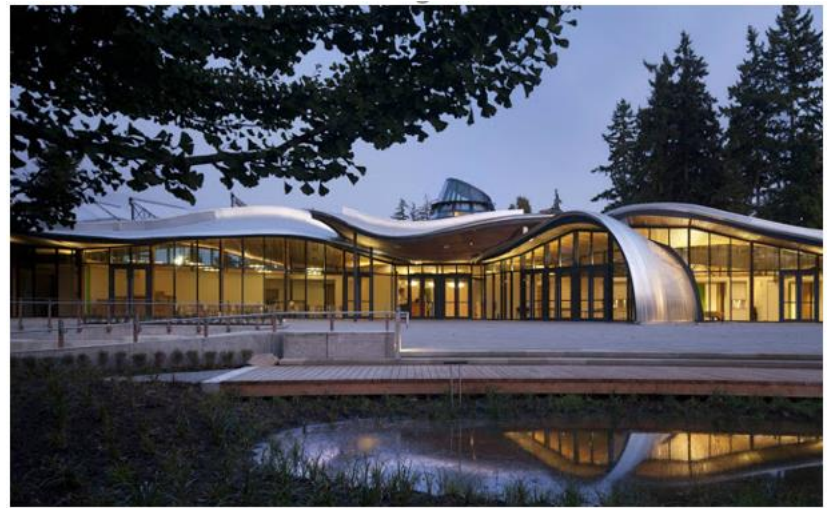

Fig. 1. VanDusen Botanical Garden Visitor Centre in Vancouer, BS [29].

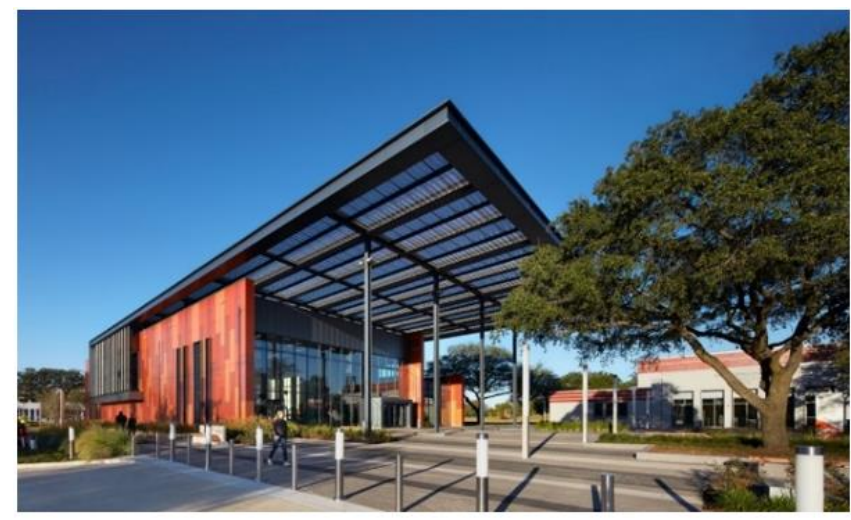

Fig. 2. Emancipation Park Expansion and Renovations Houston, USA [28].

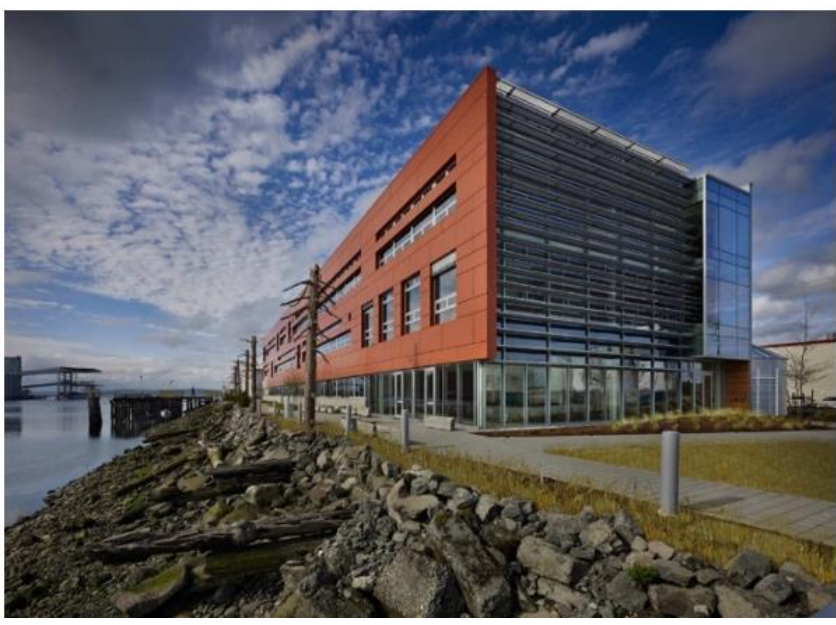

Fig. 3. Centre for Urban Waters, Tacoma, WA, USA [30].

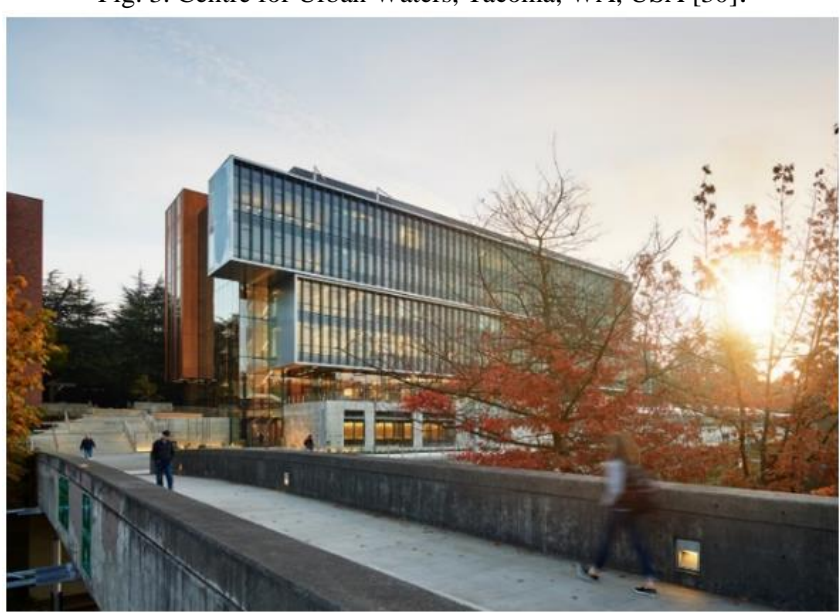

Fig. 4. Life Science Building for the University of Washington, USA 


\section{LITERATURE}

The concept of regenerative development falling under the broader context of sustainability shows some primary points of deviation from the two prevalent worldviews: the public policy (idealistic) and the private sector (Ecological modernization) [14], [4], [5]. Reference [6] groups both prevalent concepts under Technological sustainability. Explaining further that Regenerative sustainability and Technological sustainability are paradigms under the Ecological and Mechanistic Worldview respectively. The complaint about Technological sustainability which had an initial objective of rejuvenating the dilapidating environment was its decline to a worldview that was reduced nature to a machine [25]. This reductionist mindset sees nature as having part that could be dismantled into useful elements to solve man's problems [6]. They also consider man as separate from and over nature [6].

Reference [14] coherently highlighted the evolution of sustainability concept to begin from a need to create a sustainable environment led to an international consensus tagged the "public policy model". The model as expressed through various consensus document such as the Agenda 21, Habitat Agenda, and Millennium Development Goals ended up in two factions with different objectives: The first which was the "sustained development" and deviated from the primary objectives to pursue a need-based system, thereby compromising nature's integrity. The second; "Sustainable development" faction sustained the objective of creating a sustainable environment.

Furthermore, the "business model" evolved and was based on creating a means of measuring the operational limits of man in the ecosystem so to prevent exceeding that limit. The model was also criticized as still being mechanistic as they don't proffer the expected whole system application of sustainability in building and development process that should lead to mutual relationship with equal benefits between man and nature [14], [1].

Reference [14] highlighted that a grassroot intervention began to emerge under the "green building movement" and was initially neglected due to its seeming impracticability for the urban context being implemented only in small-scale and peri-urban environment. This radical ecologism of grassroot initiatives sought for a harmonious co-existence of man and nature coupled with a means of enhancing the life of all constituents of the ecosystem (man and nature). In a bid to achieve their aim, they paid evolved strategies such as renewable energy, building materials extracted from nature, urban agriculture, permaculture, evolution of alternative building methods and development such as the Ecovillage. This movement therefore served as a trailblazer to the regenerative sustainability paradigm.

The term Regenerative design and development has been described by numerous proponents of the concept beginning from [8] who first put it forward as "replacing the present linear system of throughput flows with cyclical flows at sources, consumption centers, and sinks" [8]. His concern arose from his foresight of the inevitable environmental degradation from the linear resource flow (i.e., from the use of natural resource ending up as waste product) existing since the wake of the industrial revolution [14].
[8] explained that a project can be regenerative only when it fully considers and integrates the unalloyed functioning of both the human system and the natural system where it is located into its design. Reference [5] added that this creates developments that are properly integrated into the ecosystem harmoniously without causing damage and creating a healthy and mutual benefit (positive addition) to all elements in the ecosystem (man and nature). "Regenerative" therefore describes a process that re-amends, remakes or renews its sources of energy or air, water, materials (i.e., natural resources) or any other matter [9].

Reference [33] posits that ecological design (which is a primary foundation for regenerative designs) incorporates four primary characteristics that follow "generative" principles. This "generative" principles as explained by [29] shows that they are built on common values, ethics and norms guiding individual's responsibility to the environment, they are founded on the native socio-cultural history of the place and they are dynamically evolving to allow for improvements in new culture and technology thereby allowing for the unpredictable/qualitative aspects of nature such as connection to place, equity, and aesthetics. It is on this grounds that Regenerative development is defined to mean "a system of technologies and strategies, based on an understanding of the inner working of ecosystems that generates designs to regenerate underlying life support systems and resources, through improved human and natural systems co-evolution for mutual benefits, greater expression of life and resilience without ongoing human intervention" [30].

Regenerative development is, therefore, a means by which man co-partners with the environment through his developments for continuous improvement of the health of all living organisms in the ecosystem including humans (socially, culturally, economically, psychologically, and physically) [10]. Reference [10] explains further that humans are therefore viewed as co-partners to and integral part of the ecosystem. This suggests that there is a mutual objective of repairing and improving the functional capacity of the ecosystem without any ongoing human intervention. This concept differs from the technological sustainability worldview that sees humans be over and above nature, exploiting nature for his purposes which has led to continuous degeneration [8], [15], [5], [17].

The philosophical basis of Regenerative development as illustrated by [7], and [11] among others are as follows: Man, his developments and cultural constructs are an inherent part of the ecosystems (and should not disruptively superimpose himself on other constituents of the ecosystem as himself). Man's actions should assist the self-healing processes of nature by fostering the functioning and improvement of the ecosystems and their natural cycles (such as natural resources renewal). Man's actions in his environment should be founded on the longings/desires of that environment. Therefore, maintaining the intrinsic character of the place. Finally, design and development should be seen as a continuous co-partnered process.

[32] posits that a continuous addition to the natural and social wealth then becomes the aim of regenerative development. The ecology after development becomes richer as it preserves, protects, and restores a lost abundance in the 
ecosystem. [8], and [12]. Man's exploitation is reversed, instead, he works with nature reciprocally for the mutual fulfillment of each of their purposes [13]. Wrapping up the ultimate function of any development in the built environment, (or any building) [15] and [14] suggests that the built environment becomes a means of supporting and enabling the mutual co-evolution of people with their social and biophysical environment (i.e., the whole ecological system), hence fulfilling the core tenets of Regenerative development.

Though rooted in bioregionalism and permaculture [8], the founders of Regenerative development have extended its framework to include engagements with the place and cultural system. Regenerative development, therefore, interacts with the whole social-ecological and cultural system to increase its potentials and ability to evolve [14]. The regenerative approach is physically implemented in a place by combining multiple narratives at different levels/scale of development into a meta-narrative to create principles, visions, and goals for the particular socioecological system [15]. This shows the integrative process of Regenerative development, as it develops on other sustainability frameworks such as efficient use of resources, ecological design, and resilience.

Beginning from the macro-scale (the watershed or bioregion) to the local. Regenerative design or planning process begins by reconnecting to the essence of a place by investigating the historical, cultural, ecological, and economic patterns of a place [16]. This involves an imaginative foresight of the potential wonder inherent in the place [16]. Reference [15] explains this phase in detail to involve looking back into the contextual functional identity and looking forward into the aspirations of a place (both the natural and human ecosystems) thereby, leading to these questions:

"What does Nature want to be in this place?" Here, the context of the proposed development is viewed from an ecological scale and timeframe (which spans larger than the spatial and temporal scales of most built environment projects), to pinpoint the typical core character or spirit of place, the functional identity of the system (its aspirations) and its potential. The goal here is to map the place construct alongside with special considerations in the design process through an open system in a useful way. Accuracy in getting all the flows and dynamics in the place is impossible and this opposes the uses of measures and indicator models as present in the existing technologically oriented sustainability paradigms. As highlighted by [15] searching for 'pattern clues' to interpret the systemic connections in the place and its landscape is the only valid tool in this case. The constituents of the natural ecosystem from which patterns are investigated here include the vegetation, the wildlife, geological structures, hydrological structures, the local climates, available minerals, etc.

How the contributions of the users/residents (the human ecosystem) to the needs and functional identity of the place can serve in sustaining its core character and fostering evolution and regeneration is the next question [14]. This has been achieved through community stakeholders' involvement [5]. The mind-set of a man being the controller or manager of the ecosystem resources must be changed to that of a gardener assisting other aspects of the ecosystem to be replenished [15] This must be done with a change in the value system of the users/residence in the place, hence the need for community dialogue in the pre-design stage [15]. Human ecosystem elements include typical traditions/customs, physical infrastructures such as buildings and constructed artifacts, values/ideas, cultural and economic activities, forms of association/interaction. Lastly, what mechanism of continuous feedback, learning and monitoring key indicators of change as the development is juxtaposed with its long-term aspirations? [7]

The process continues with the setting of performance criteria to realize the potentials in the place i.e., creating a regenerative capacity for the whole system (not individual elements in the system) [15]. These criteria are used to outline specific regenerative design strategies for the project at hand [14]. Reference [15] further describes the features of these goals as one, being sourced from and typical to the place: the inherent resource bank (energy, materials, and support systems) in a place must be used and renewed to a continuing and increasing abundance. Two, it must also be able to evolve beyond just regenerating the degradation of the place to a continuous improvement of the ecosystem health. Three, they must also include the human aspirations in the locality. These aspirations are derived from the distinctiveness of the place as described above and the meaning attached to this distinctiveness by the residence in the place. These goals combined are then used to ensure that buildings are orchestrators of a regenerative developmental process in the ecosystems in which they are located.

The final stage is a continuous harmonization of solutions and evolving patterns as the whole system develop [15]. There must, therefore, be a co-evolution of the human and natural system as it reorganizes itself, reintroduces new patterns and increases in complexity [5].

These Principles and processes are now been facilitated with the creation of new design theories and frameworks such as BNIM's (Berkebile Nelson Immenschuh McDowell) REGEN tool proposed by the US Green Building Council (USGBC) [17], CLEAR's (Centre for Living Environments and Regeneration), LENSES (Living Environments in Natural, Social, and Economic Systems) framework proposed by Colorado State University's Institute for the Built Environment and the Rocky Mountain Institute [4] and the PERKINS+WILL framework created by PERKINS+WILL and the University of British Columbia [5]. They all employ similar regenerative design strategies in their application [18].

\section{A. Regenerative Design Strategies}

Reference [5] defines the systemic context for a holistic application of regenerative development to cover the environmental, social, cultural, and economic contexts. Reference [12] further explained that regenerative sustainability strategies on functional levels is composed of ecological designs, building ecology, and ecological engineering. They form the basis of implementing the principles and points at nature as man's "mentor, model and measure". In addition, [12] highlighted two levels for the application of regenerative strategies: Firstly, the use of ecosystem or biological species to replace mechanical 
structures in designing or retrofitting the environment. Secondly, the application of ecological designs which are designs that prevents the deteriorating effects of developments on the environment by its integration into nature's living operation and processes.

More plainly, [19] groups the implementation of any ecological design into four basic infrastructures necessary for a whole system, multi-faceted, and integrative application of regenerative development principles. They are the green (flora), red (human), blue (water) and grey (built environment) infrastructures.

The green infrastructure consists of nature's intrinsic utilities: an interweaving of nature's wealth to sustain and improve the natural ecosystem values and functions. The green infrastructure caters for cleaning up air and water, creation of habitat for a large range of fauna, amelioration of climate change, enhancement of energy use, protection of water sources and reduction of the heat-island effect in urban areas amongst other functions [19] Its functional design components include Ecology/nature, climate, ecosystems, flora/fauna, natural resources, physical environment, biogeochemical cycles, etc. [9].

The Red (human) infrastructure includes the human community, its built environment (building/housing type, and artifact, etc.), hardscapes and regulatory systems (laws, regulations, ethics, etc.) [19] They are systems that enhance human wellbeing (emotionally, spiritually, culturally, socially, financially, etc.) e.g., industrial production with zero impact on man, economic systems, regulation and legislation, incentives/penalties, mobility/transport concepts, materials/enclosures, products/food, etc. Its functional elements include Mans activities, commerce, economic systems, lifestyles, mobility, recreation, food, and diet.

The blue infrastructure includes systems that improve sites hydrology through proper water cycle management strategies to close the loop. These include rainwater harvesting and recycling, surface water retention within the site for the recharging of groundwater/aquifers through pervious surfaces, filtration beds, retention ponds, and bioswales. Recovery and reuse of grey and black water used in the built system. Its functional design elements include: Rain/dew and ground waterways, lakes, Infiltration bioswale, sustainable drainage, detention ponds, Green street infiltration planter, permeable paving, rain garden, stormwater, and wetland carnal, etc. [19].

The grey infrastructure includes the usual sub-structural, super-structural building component and engineering infrastructure such as roads, drains, sewerage, telecommunications, and energy and electric power distribution systems which must be integrated seamlessly into the green infrastructure as well as designed sustainably [19]. Examples include energy systems, clean technology, renewable energy, smart grid IT network, transportation/circulation system, carbon-neutral materials, and waste management systems, etc. design strategies here are divided into three phases which includes: A flexible structural system (slabs, columns, and beams), selection of appropriate regenerative design elements and integration of specific regenerative materials and products for building [9].

\section{RESUlTS AND DisCUSSION}

The Case studied built with the Perkins+Will regenerative design frameworks shows a deep consideration of place potentials and patterns in their designs. The patterns were employed in outlining their projects goals and aspirations to facilitate contextual and regenerative development. Some of these place patterns and potentials are outlined below with their resultant project aspiration:

In the design and renovation of Emancipation Park, Fig. 1 Perkins+Will identified a dichotomy between the existing building and the landscape. The buildings had no connection to the landscape; hence it was regarded as boring and tiring in its look [20] Looking back to the historical context of the Park, they identified the degeneration of the expected social purpose of the park i.e., to commemorate the history of freedom from slavery [20] There was a diminishing cultural identity with this original purpose. There was a perceived potential, fusing the historical context/purpose of the building with the needs of the present and future community. This where the patterns originating from the place that evolved the needed regenerative design strategies, hence a contextual one.

The design of the Vandusen Botanical Garden visitor center shown in Fig. 2 was born of the aspirations to have an environmentally and socially conscious community [21] The undulating pattern of the site combined with the need to create a public community understanding of the equilibrium between human and natural ecosystems. These patterns including the concept of the building form gotten from a native orchid plant were used to select the appropriate regenerative strategies for the development. Another goal was to increase the natural vegetation despite the newly developed building [21].

The potentials of becoming a beacon on the water, the cultural capability of maximizing its closeness to the waterways, the shoreline esplanades and maximizing open spaces all created goals and aspirations for the Centre for Urban Waters shown in Fig. 3. The project also aspired to provide examples of regenerative and sustainable placebased design strategies [32].

As these potentials and patterns of place are mapped out, they lead to the selection of specific strategies for a placebased design and development. The Regenerative strategies employed in the current practice of regenerative development gotten from the examined case studies are grouped into the four infrastructures as given by [19] This will enable coverage of various strategies used to achieve a whole system and integrative design and development. Below are some place-based design strategies employed in the cases.

The designers of the park organized all the commemorative buildings along a large entry plaza called the Founders Promenade [20] this brings about socio-ecological interaction between fellow humans and nature. The creation of an indoor/outdoor stage is a strategy set up to connect the interior and exterior of the community center. As the entrance foyer is used for an outdoor stage for the open area in front of the building which is punctuated by trees overshadowing sitting blocks, there is a flow between the interior and exterior of the building providing for many 
possible functions Fig. 5.

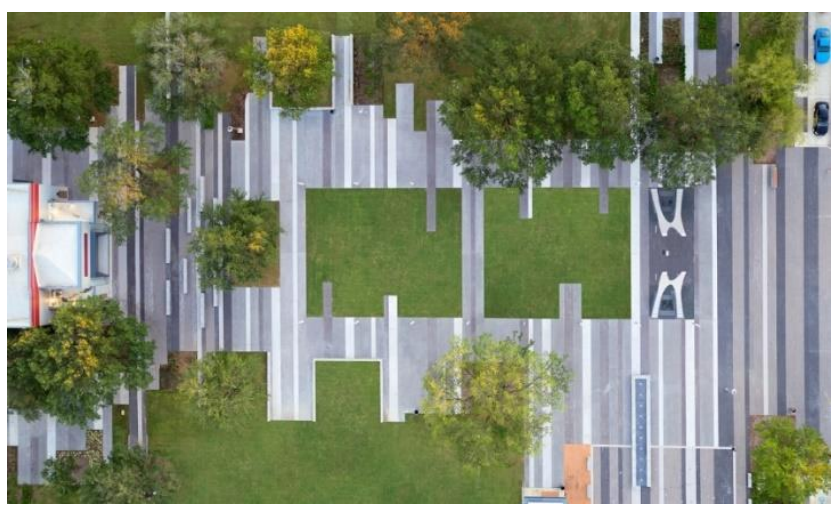

Fig. 1. Flowing Texture hardscape designed to connect open and builtup spaces [28].

In connecting the green and grey infrastructures of the emancipation park, Perkins+Will employed a flowing texture protruding and receding from the open green spaces in the park, this is said to activate and connect perimeter zones around the buildings [20] as seen in Fig. 6. In connecting the historical context of the surrounding buildings with the present design to give a cultural identity, panels used for the façade system and the foundation walls were designed with the same color as historic homes in the neighborhood. This creates a cultural identity (a sense of place) connecting the new design with its neighborhood. Biomimicry was employed in the project, still emphasizing a contextual design; the native lives oak trees at the front of the large entrance porch were mimicked in scale in the finish patterns on the entrance porch. This supports the biophilic nature of man in interacting with nature.

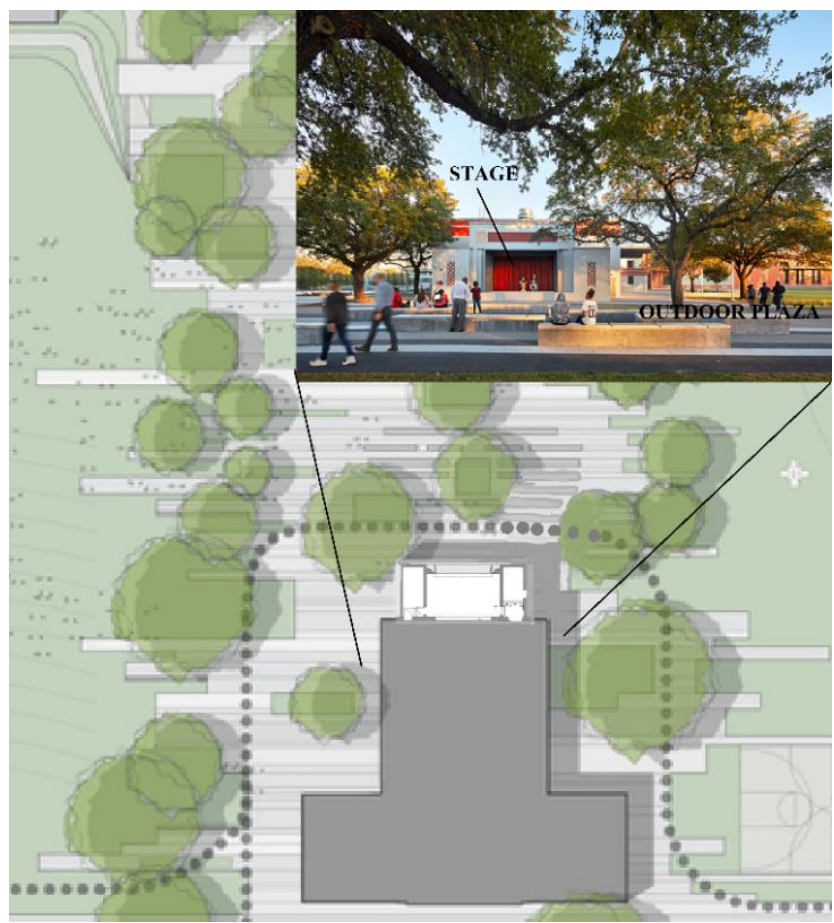

Fig. 2. Indoor/Outdoor stage and viewing plaza. Adapted from [28].

The Vandusen botanical garden visitor center employed strategies of connecting vegetation's to avoid a termination of the flow of indigenous biological species. This inspired the connection of ground level to roof level through green surfaces that reoccupy the footprint of the building on the ground. This creates a large surface area of vegetation. As regenerative development employs strategies that renew buildings resources, various passive and active systems were employed to recycle and reuse the building's wastes and resources found on the site respectively. Biomimicry for the cultural representation of the building was employed in the building form which mimics a native orchid plant. The roof was designed to undulate in the form of the plant petals. This creates a sense of place in the design for the cultural identity of the building. Summarily, more detailed design elements under the aspects of implementing regenerative design strategies are given below.

\section{A. Green Infrastructures}

Provision of Greenhouses: this was used to enhance biological diversity around the building providing numerous living species. The use of Green Walls and Green roofs, Green floors and terraces/balconies. Seat outs in between plantings and soft landscape were used to enhance users' interaction with nature. Indigenous and rare trees, shrubs and plants were left untouched by carefully mapping out the building footprints on the site. As shown in Fig. 7, Roof gardens were used to replace the vegetation displaced by the building and also to integrate nature into the architecture. Connection of Roof garden to the ground plane was made to facilitate local species dominating the roof garden. The center for Urban waters described above employed the used of tree snags along its waterways to create habitat for local fauna species thus creating biodiversity on the site.

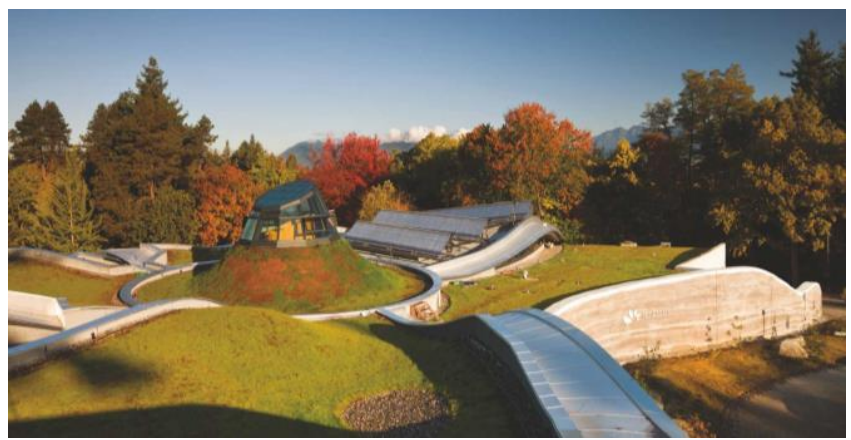

Fig. 3. Green Roof and garden connected to ground floor Level for Green Infrastructures [29].

\section{B. Grey Infrastructures}

As seen in the Vandusen botanical center, passive design strategies employed include Geothermal boreholes, entire solar photovoltaics roofs that produces as much as 11,000 $\mathrm{kWh}$ and solar hot water tubes that produce as much as $176,000 \mathrm{kWh}$. These elements were combined to achieve a net-zero energy use for the building on an annual basis. Sunshading of facades especially those glazed to aid natural lighting as shown in Fig. 8. Vertical glass solar fins installed on the building's exterior to generate electricity to light as much as 12,400 square feet of offices throughout the year. 


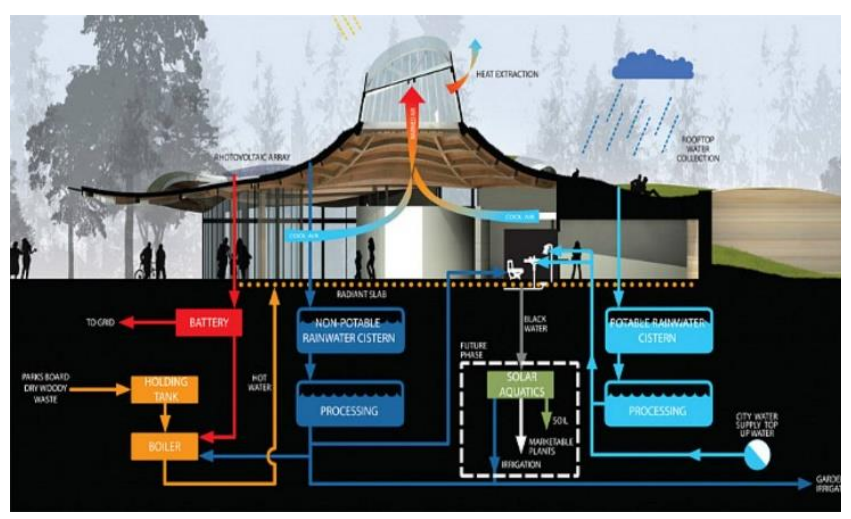

Fig. 4. Analysis of Green, Grey and Blue Infrastructures [29].

Other Energy reduction means includes the use of exterior sunshades on high-performance glazing, ground source heat pumps that charges radiant floor slabs reduces heating and cooling energy. Smart sensors for light control also provide minimal energy for lighting. Natural ventilation systems such as operable atriums that operates as a solar chimney that provides air movement through convection energy thereby providing ventilation, operable windows. The use of materials with low carbon footprint, flexibility, ease of disassembly and reassembly, recyclability, durability, and absence of VOC's (volatile organic compounds). Example, as used in the case studies, includes rammed earth walls glued laminated timber (glulam) for the roof construction. Materials such as aluminum plate rain screen, corrugated metal sidings, and shading devices were obtained from recycled products. Easily modularized construction system was used to enhance flexibility, assembly and disassembly characteristics in the designs. Site benches were made from recycled granite curbs gotten from local landfills. Ceilings were made from milled and reused heavy timbers from the site.

\section{Red Infrastructures}

Social strategies: Emphasis on indoor/outdoor connectivity through the use of mobile walls and furniture to achieve flexible and adaptable spaces. The design of a converging point for all buildings in a complex enhances social interactions.

Cultural elements and Sense of Place: biomimicry of site elements such as trees, stones, and soil pattern. The use of indigenous site materials and the mimicking of colors of adjourning-built environment with similar color patterns all create a sense of place for a project. The use of organic forms from contextual elements creates a cultural identity with the site by the community.

Economic Strategies: The trade of surplus energy gotten from the building has been a major economic strategy employed in most regenerative design projects.

\section{Blue Infrastructures}

The provision of rainwater and storm water collection chambers passing through permeable surfaces (paving, rain gardens and green roofs) for filtration and reuse system for the building grey water needs. Treatment of black water by bioreactor and a series of bioswale fields and gardens for percolation and natural treatment turns it to clean greywater which could be reused by the building or released back into a nearby pool or stream.
The foregoing narrative on the studied cases shows the process of creating regenerative development as firstly, mapping of place-specific characteristics and potentials, secondly, creating aspirations and goals for the development based on the identified patterns and potentials, thirdly, integrating both the natural and the human ecosystem through the proposed development (buildings/landscape) and finally creating a system for continuously evolving harmony and integration between both systems.

\section{CONCLUSION}

This paper has presented the meaning, underlying principles, and facets involved in creating a regenerative development. The highlighted regenerative design strategies utilized in the cases integrated the human and the ecological systems within and outside the building with the architectural element. The building then becomes a tool of renewing the ecosystem and not just a human-centered edifice. The strategies gleaned from each of the cases depicts the practicability of implementing regenerative design principles holistically in building developments thereby facilitating an understanding of how regenerative development is applied in all its phases and facets. A further area of research should attempt to quantify the extent to which each of these strategies regenerates and restores the ecosystem in around buildings. This will provide more justification for the use of regenerative design principles in the development of the built environment. Overall, Regenerative development requires a place based, integrative and holistic design strategy designed to continuously evolve. Clues and Potentials of the places drawn out by mapping the place patterns set out the foundation for a placed based development. The fusing of design elements for both human and ecological benefits made the developments integrative. The meld between the green, blue, grey and red infrastructures based on place patterns and potentials created a holistic development. The applied strategies have not been able to fully describe a mutually evolving ecosystem (especially the human system).

\section{RECOMMENDATIONS}

1. The inclusion of Regenerative design principles in building codes and standards is a great necessity for a wide application of the concept in designs since it is of great benefit to the whole ecosystem.

2. The creation of indigenous Assessment framework, models, and tools for the examination of Building designs to meet up with regenerative design standards will also assist in a wide application of the concept.

3. Various regenerative elements and materials as highlighted are indigenous only to foreign locations, more research on locally available materials and their application in the construction of all elements in a building is of great necessity.

4. Existing Buildings assessed to create an imbalance in the functioning of the biosphere should be retrofitted regeneratively to remedy the ecosystem around them from further degradation. 


\section{REFERENCES}

[1] J. Robinson and R. J. Cole, "Theoretical Underpinnings of Regenerative Sustainability," Building Research and Information, 2014

[2] K. Katola and B. Goy, "The "Green Architecture" Definition Development in Modern Projecting and Building," Housing Environment, pp. 64-69, 2015.

[3] Y. Gorji Mahlabani, F. Shahsavari and M. Z. Alamouti, "Ecovillage, A Model of Sustainable Architecture," Journal of Fundamental and Applied Sciences, vol. 8, no. 3S, pp. 1835-1847, 2016.

[4] J. M. Plaut, B. Dunbar, A. Wackerman and S. Hodgin, "Regenerative design: the LENSES Framework for buildings and communities," Building Research \& Information, vol. 40, no. 1, pp. 112-122, 2012.

[5] R. J. Cole, P. Busby, R. Guenther, L. Briney, A. Blaviesciunaite and T. Alencar, "A regenerative design framework: setting new aspirations and initiating new discussions," Building Research \& Information, vol. 40, no. 1, pp. 95-111, 2012.

[6] A. Kambo, R. Drogemuller and P. Yarlagadda, "Ecological Worldview and Regenerative Sustainability Paradigm," in In International Journal of Advances in Science, Engineering and Technology (IJASEAT),Institute of Research and Journals, Toronto, Canada, 2016.

[7] B. Reed, "Shifting from 'sustainability' to regeneration," Building Research \& Information, vol. 35, no. 6, p. 674-680, 2007.

[8] J. Lyle, Regenerative Design for Sustainable Development, Wiley, Hoboken,: NJ, 1994.

[9] S. Attia, "Design Principles of Regenerative Design," in Regenerative and Positive Impact Architecture, SpringerBriefs in Energy. Springer, Cham, 2018, pp. 19-32.

[10] S. Jenkin and P. Zari, "Rethinking our Built Environments: Towards a Sustainable Future. Manatu Mo Te Taiao," Ministry for the Environment, 2009.

[11] H. Girardet, "Regenerative Cities," World Future Council and HafenCity University, Hamburg, 2010.

[12] S. Van der Ryn and S. Cowan, "Ecological Design 10th Anniversary, 2nd edn," Island Press, Washington, DC, 2007.

[13] W. McDonough and M. Braungart, "Cradle to Cradle," North Point, New York, NY, 2002

[14] C. du Plessis, "Towards a regenerative paradigm for the built environment," Building Research \& Information, vol. 40, no. 1, pp. 722, 2012.

[15] P. Mang and B. Reed, "Regenerative Development and Design. Encyclopedia Sustainable Science and Technology," I. 8855. 10.1007/978-1-4614-5828-9_303, 2012.

[16] N. S. Mang, "Toward a regenerative psychology of planning," Unpublished doctoral thesis, Saybrook Graduate School and Research Centre, San Francisco, CA, 2009.

[17] P. Svec, R. Berkebile and J. A. Todd, "REGEN: toward a tool for regenerative thinking," Building Research \& Information, vol. 40, no. 1, pp. 81-94, 2012.

[18] W. Craft, L. Ding, D. Prasad, L. Partridge and D. Else, "Development of a regenerative design model for building retrofits," in International High-Performance Built Environment Conference- A Sustainable Built Environment Conference 2016 Series (SBE16), iHBE, 2017.

[19] K. Yeang, "Strategies for Green Design," in International Conference on Sustainable Buildings Asia, 2009.

[20] Perkins+Will, "Emancipation Park Expansion and Renovation/Perkins+Will," 14 February 2018. [Online]. Available: https://www.archdaily.com/889059/historic-emancipation-parkperkins-plus-will/>ISSN 0719-8884. [Accessed 22 July 2019].

[21] Perkins+Will, "Vandusen Botanical Garden Visitor Centre by Perkins+Will," 6 June 2013. [Online]. Available: https://aasarchitecture.com/2013/06/vandusen-botanical-gardenvisitor-centre-by-perkinswill.html/. [Accessed 22 July 2019].

[22] Perkins+Will, "Centre for Urban Waters/Perkins+Will," 23 February 2011. [Online]. Available: <https://www.archdaily.com/112190/center-for-urban-watersperkins-will/>ISSN 0719-8884. [Accessed 22 July 2019].

[23] Fatoba, J. O.; Osadebe, C. C.; Obrike, S.; "Hydraulic Characteristics of a Typical Basement Complex Aquifer in Ajaokuta, South-Western Nigeria," Ife Journal of Science, vol. 7, no. 2, pp. 297-314, 2005.

[24] Meteoblue, "Climate (modelled) Ajaokuta," 15 June 2019. [Online]. Available: https://www.meteoblue.com/en/weather/historyclimate/clmatemodell ed/ajoakuta_nigeria_2351470.

[25] F. Capra, The web of life: A new scientific understanding of living systems, New York, NY: Anchor Books, 1996.

[26] MBDC, " Overview of the cradle to cradle certified CM product standard V3,” McDonough Braungart Design Chemistry, 2014.
[27] B. Bakshi, Gutowski, T. G. and D. Sekulic, "Thermodynamics and the destruction of resource.," 2011.

[28] D. V. S. Kasper, "Redefining Community in the Ecovillage," Human Ecology Review, vol. 15, no. 1, pp. 12-24, 2008.

[29] B. Hakim, "Generative processes for revitalizing historic towns or heritage districts," Urban Design International, vol. 12, no. 2-3, p. 87 99, 2007.

[30] I. C. Abazuonu and K. C. Okolie, "Regenerative Design Practices in Nigeria: A Case Study of Ngozika Housing Estate, Awka, Anambra State.," Journal of African Studies, vol. 7, no. 1, pp. 80-100, 2017.

[31] M. P. Zari, "Regenerative Design for the Future," BUILD, vol. 115 , pp. 68-69, 2010

[32] J. Birkeland, Positive Development. From Vicious Circles to Virtuous Cycles through Built Environment Design, London: Earthscan, 2008.

[33] M. Resnick, "Thinking like a tree (and other forms of ecological thinking)," International Journal of Computers for Mathematical Learning, vol. 8, p. 43-62, 2003.

[34] B. Reed, "Shifting from 'sustainability' to regeneration," Building Research \& Information, vol. 35, no. 6, p. 674-680, 2007.

[35] Perkins+Will, "Life Sciences Building for the University of Washington/Perkins+Will," 12 March 2019. [Online]. Available: <https://www.archdaily.com/912260/life-sciences-building-for-theuniversity-of-washington-perkins-plus-will/>ISSN 0719-8884 [Accessed 22 July 2019]. 